\title{
Move Confirmation and Teaching Strategy Identification of English Student-Teachers' Lesson Plans in the Philippines: A Rhetorical Framework for Novice Teachers
}

\author{
Issra Pramoolsook \\ Suranaree University of Technology \\ Nakhon Ratchasima, Thailand \\ William D. Magday, Jr. \\ Suranaree University of Technology \\ Nakhon Ratchasima, Thailand
}

\begin{abstract}
Lesson planning is one of the most important skills of a teacher in the Philippines. The Department of Education (DepEd) mandates that a teacher is not allowed to teach without a lesson plan. Hence, all the Teacher Education Institutions (TEIs) ensure that every education student can produce well-planned lessons even before the Teaching Internship course. Despite its relevance, no one has attempted to investigate the lesson plan structure using move analysis. Moreover, a preliminary survey reveals that many of the English student-teachers find it difficult to produce lesson plans. Therefore, this study explored 22 Detailed Lesson Plans (DLPs) produced by English student-teacher graduates of a TEI through move confirmation and teaching strategy identification, which are based on the 5-part lesson plan structure prescribed by the Commission on Higher Education (CHED) for the student-teachers. The study is anchored on Swalesean genre analysis that combines rhetoric and linguistics to explain genre as grounded in shared communicative purposes and discoverable through text analysis. Based on the analysis, the five parts or moves were confirmed with their constituent teaching strategies and teaching strategy cycle identified. The findings may provide TEI teachers with insight into effective instructional strategies to help students acquire pragmatic knowledge of the rhetorical structure of lesson plans. A Lesson Plan Framework for English novice teachers is proposed as a guide to offer a frame for structuring their planning of the lessons and a pool of words that can help them in writing the lesson plans.
\end{abstract}

Keywords: move confirmation; teaching strategy identification; teacher education program; lesson plan; genre analysis. 


\section{Teacher Education Program in the Philippines}

The Teacher Education Program (TEP) in the Philippines is the teaching and training provided to pre-service teachers before they become in-service teachers and undertake any teaching-related works. The Bachelor of Secondary Education (BSEd) program, one of the baccalaureate programs under TEP, has curricular components, which are General Education courses, Professional Education courses, and Specialization/Content courses. One of the valuable components of these programs is the Experiential Learning Course (ELC) that has six units of Field Study (FS) courses and another six units of Teaching Internship (Commission on Higher Education [CHED], 2004). In the Teaching Internship course, the student-teachers are deployed in the public secondary schools and undertake teacher-related training, one is the production of Detailed Lesson Plans (DLPs), under the supervision of their respective cooperating teachers. Aside from the cooperating teachers, the headteachers and the school principals also supervise the student-teachers during the Teaching Internship course. This group of in-service teachers ensures that the student-teachers participate actively in school-related activities and project a noble image at all times by observing DepEd's Code of Ethics, proper dress code, and punctuality in all activities (Department of Education [DepEd], 2007). They are responsible for checking and approving the lesson plans, which are produced by the student-teachers 1-2 days before teaching the lesson. The 5-part lesson plan policy (Objectives, Subject Matter, Procedure, Evaluation, and Assignment) mandated by CHED $(2004,2017)$ serves as the guide for the student-teachers in producing the lesson plans. In each part, there are identified subparts or teaching strategies as proposed in this investigation to achieve the communicative goal of every part. There are three formats of a lesson plan, which are 1) the Daily Lesson Logs (DLLs) or outline format which has only keywords as a teacher's guide in teaching, 2) the semi-detailed format, and 3) the Detailed Lesson Plans (DLPs). The first format is only for in-service teachers who are classified as seasoned teachers like cooperating teachers, headteachers, etc. Thus, the Teacher Education Institutions (TEIs) and cooperating schools do not allow the student-teachers to follow such format. The Department of Education (DepEd) orders that only newly-hired teachers including studentteachers without professional teaching experience are required to prepare Detailed Lesson Plans (DLPs) since the practice would help them organize and manage their lessons. Once the newly-hired teachers obtain a Very Satisfactory or Outstanding rating in their Individual Performance Commitment and Review (IPCR) based on the Philippine Professional Standards for Teachers (PPST), they will be allowed to transition to the use of DLLs, which incentivizes them to perform better (DepEd, 2017). The IPCR is an annual evaluation that is performed by the school principals and headteachers. The results are then forwarded to the school division superintendent for validation, and finally to the DepEd Division Office for approval and announcement. The DepEd mandates the use of DLLs, which utilizes a standard template that covers a week's worth of lessons in a tabular format, while DLPs are prepared by the novice teachers daily. The main parts of DLLs are also similar to DLPs. The only difference is that DLPs are more detailed and much longer than DLLs (DepEd, 2016). No teacher education students are allowed to graduate without finishing the 
required number of hours for Teaching Internship and accomplishing requirements, one example is the internship portfolio, a package where the lesson plans are taken (CHED, 2017).

\subsection{Lesson Plan}

In recent years, there have been a number of research studies (Yildirim, 2003; John, 2006; Williams, 2009; Wyatt, 2011; Rusznyak \& Walton, 2011; Ruys, Keer \& Aelterman, 2012; Taghipour, 2013; Moradana \& Pourasadollahb, 2014; Thephavongsa, 2019; Cavanagh, et al., 2019) about the importance of lesson plans in teaching. These researchers claiming that a lesson plan is the heart of effective teaching in which the teacher indicates the objective of the lesson, the instructional materials to be taught, and the effective methods to be applied to achieve the objectives.

Conversely, John (2006) and Rozelle and Wilson (2012) found that some English teachers still face difficulties in developing effective and systematic lesson plans. This finding ties well during the focus group interview conducted as a part of this study with the participants who stated that even if they know the main parts of a lesson plan, they have still difficulties in constructing the subparts of each main part (focus group interview, August 10, 2018). Therefore, it is necessary to investigate the structure of the lesson plans produced by the student-teachers during the Teaching Internship course through move confirmation and teaching strategy identification, which is inspired by Swales' (1990) move analysis. This analysis involves identifying the series of moves that make up the genre from a representative sample of texts. Each move is a distinctive communicative act that is aimed to attain one communicative function and can be subdivided into different steps or rhetorical strategies (Hyland, 2000). The steps or strategies of a move primarily function to achieve the purpose of the move to which it belongs (Biber, Conner \& Upton, 2007). In this investigation, the moves are the main parts of the lesson plan, and their constituent subparts are considered as teaching strategies. While many genre researchers (Peacock, 2002, 2011; Samraj, 2002; Yang \& Allison, 2003; Lores, 2004; Kanoksilapatham, 2005; Lim, 2006; Ozturk, 2007; Li \& Ge, 2009; Huang \& He, 2011; Zhang, Thuc \& Pramoolsook, 2012; Basturkmen, 2012; Jaroongkhongdach, Todd, Keyuravong \& Hall, 2012; Stoller \& Robinson, 2013; Nguyen \& Pramoolsook, 2014, 2015; Shulzhe, 2016) have examined the rhetorical structures of theses, dissertations, research articles and other academic texts across disciplines following the perspective of move analysis, however, as yet, no research studies have been conducted on investigating the structure of lesson plans. The present study, therefore, attempted to contribute a piece of new knowledge to genre studies and a new methodological effort for genre-based analysis by exploring the lesson plans within the discipline of Bachelor of Secondary Education (BSED)-English. Specifically, it explored the moves to confirm whether the student writers followed the five parts prescribed by CHED, and it also identified the constituent teaching strategies used to achieve these parts. The objective of this study, therefore, translates into these two research questions:

1. To what extent do the moves of the lesson plans produced by the BSEdEnglish student-teachers during their Teaching Internship conform with the 
CHED policy on lesson planning?

2. What are the constituent teaching strategies used to achieve those moves?

\section{Method}

\subsection{Data Collection}

The first step to get hold of the internship portfolios, in which the lesson plans are packaged as one of the components, was to distribute the request letters asking for permission to the College of Teacher Education (CTE) Dean, and Secondary Education Department (SEd) Chair of the Nueva Vizcaya State University (NVSU), Bayombong, Nueva Vizcaya, Philippines. The investigators used a convenience sampling technique, and to address other factors that might affect the writing of the lesson plans like availability of electricity, internet, computers, and other needed equipment, the investigators ensured that all the student-teachers involved in the study were from cooperating schools situated in the cities and that they all stayed in apartments or school dormitories.

2.2 Selection and Management of the Lesson Plan Corpus

In this study, 22 Detailed Lesson Plans (DLPs) were investigated. The texts were taken from the final demonstration teaching of the student-teachers. The total number of texts as the actual corpus is 22. Table 1 shows the number of BSEdEnglish internship portfolios selected from Batch 2014 to Batch 2018 and the actual sampling numbers of lesson plans.

Table 1. Number of internship portfolios and actual corpus selected

\begin{tabular}{rcc}
\hline Batch & Portfolios & $\begin{array}{c}\text { Actual } \\
\text { Corpus }\end{array}$ \\
\hline 2014 & 4 & 4 \\
2015 & 4 & 4 \\
2016 & 4 & 4 \\
2017 & 4 & 4 \\
2018 & 6 & 6 \\
Total & 22 & 22 \\
\hline
\end{tabular}

There were three intentions of including the BSEd-English graduates of Batch 2014 to Batch 2018 with different numbers of texts. First, for having six portfolios from Batch 2018, is that this group of students was the newest batch of graduates, and the possible impact of the proposed pedagogical implications would be more timely. Second, it is necessary to have a corpus size across the five batches to be able to elicit more reliable data that could strengthen the findings of the investigation. Third, the investigators are aware that there is a reshuffle of the overall in-charge of the Teaching Internship course every three years, so the student-teachers receive different instruction from whoever the overall in-charge during their Teaching Internship course, who is the Teaching Internship Chair.

\subsection{Analysis Process}

First, the researcher identified the moves in the texts according to their communicative purposes then these were checked to confirm whether and to what extent do the student-teachers followed the lesson planning structure prescribed by CHED. Second, after analyzing the moves, the investigators 
identified the teaching strategies in each move. The investigators used simple word-level analysis since the moves were revealed in the five main parts of the lesson plans, and the teaching strategies were investigated using sentence-level analysis. Therefore, any sentence or group of sentences that supported the communicative purpose in each move was classified into the same teaching strategy until the new teaching strategy occurred in the next sentence. The moves and teaching strategies were marked manually on the photocopied lesson plans. The criteria for move confirmation and teaching strategy identification frequency classification of the lesson plans were based on Kanoksilapatham (2005). So, if a move and teaching strategies occur in all 22 lesson plans, which account for $100 \%$, it is 'Obligatory'. The move occurrence from $60-99 \%$ is 'Conventional', and the frequency of a move below $60 \%$ is 'Optional'. As a starting point for move confirmation analysis, the five main parts (e.g., Objectives, Subject Matter, Procedure, Evaluation, and Assignment) of a lesson plan as mandated by CHED served as the reference framework to confirm whether the student-teachers abided such policy or not. These moves also served as a guide to identifying the teaching strategies. Data on the focus group interview with the five participants (Chaaban et al., 2019) were utilized in discussing and classifying the results of the study.

\subsection{Inter-rater reliability}

For the reliability of the findings, the services of two language professors who have had a long experience in handling the Teaching Internship course and have linguistic sophistication (Crookes, 1986) were tapped to do the final scrutiny after the initial analysis of the investigators. The results were compared following the standard simple agreement of Neuendorf (2002).

\section{Results and discussion}

Table 2 below summarizes the findings of the study on moves and their constituent strategies as well as their frequencies that prescribe their statuses. Communicative functions, excerpts, and rhetorical structures are presented.

Table 2. Summary of moves and teaching strategies of the lesson plans

\begin{tabular}{|c|c|c|c|}
\hline \multirow[b]{2}{*}{ Moves \& Teaching strategies } & \multicolumn{3}{|c|}{ Lesson Plan Corpus } \\
\hline & $\mathbf{f}$ & $\%$ & Status \\
\hline M1: Setting Objectives & 22 & 100 & Obligatory \\
\hline $\begin{array}{l}\text { TSA: Providing the starting signals or lead-in } \\
\text { statements }\end{array}$ & 22 & 100 & Obligatory \\
\hline TSB: Listing the lesson goals as items & 22 & 100 & Obligatory \\
\hline M2: Introducing Subject Matter & 22 & 100 & Obligatory \\
\hline TSA: Specifying the topic to be discussed & 22 & 100 & Obligatory \\
\hline $\begin{array}{l}\text { TSB: Indicating the references of the textbooks } \\
\text { to be used }\end{array}$ & 22 & 100 & Obligatory \\
\hline $\begin{array}{l}\text { TSC: Listing the instructional materials to be } \\
\text { utilized }\end{array}$ & 22 & 100 & Obligatory \\
\hline
\end{tabular}




\begin{tabular}{|c|c|c|c|}
\hline M3: Describing Procedure & 22 & 100 & Obligatory \\
\hline TSA: Listing the activities & 22 & 100 & Obligatory \\
\hline TSB: Offering the guiding scripts & 22 & 100 & Obligatory \\
\hline $\begin{array}{l}\text { TSC: Providing the activities' instructions using } \\
\text { imperatives }\end{array}$ & 22 & 100 & Obligatory \\
\hline TSD: Predicting the students' responses & 22 & 100 & Obligatory \\
\hline TSE: Preparing the classroom/students & 19 & 86.4 & Conventional \\
\hline TSF: Activating the students' prior knowledge & 20 & 90.9 & Conventional \\
\hline TSG: Drawing the students' attention to the new & & & \\
\hline lesson & 17 & 77.3 & Conventional \\
\hline TSH: Presenting the new topic & 22 & 100 & Obligatory \\
\hline TSI: Discussing the topic & 22 & 100 & Obligatory \\
\hline $\begin{array}{l}\text { TSJ: Praising the } \\
\text { answers/performance }\end{array}$ & 22 & 100 & Obligatory \\
\hline $\begin{array}{l}\text { TSK: Foreseeing the possible classroom scenes } \\
\text { using parentheses }\end{array}$ & 18 & 81.8 & Conventional \\
\hline TSL: Assigning the students' roles & 22 & 100 & Obligatory \\
\hline TSM: Addressing the students & 22 & 100 & Obligatory \\
\hline TSN: Mentioning the scoring rubric/system & 13 & 59.1 & Optional \\
\hline $\begin{array}{l}\text { TSO: Indicating the figures/images related to } \\
\text { the activities }\end{array}$ & 18 & 81.8 & Conventional \\
\hline TSP: Asking closing questions & 9 & 40.1 & Optional \\
\hline $\begin{array}{l}\text { TSQ: Assessing the students' knowledge about } \\
\text { the lesson }\end{array}$ & 20 & 90.9 & Conventional \\
\hline TSR: Integrating the values of the lesson & 21 & 95.5 & Conventional \\
\hline TSS: Preparing the students for Move 4 & 11 & 50 & Optional \\
\hline M4: Detailing Evaluation & 22 & 100 & Obligatory \\
\hline $\begin{array}{l}\text { TSA: Providing the instructions using } \\
\text { imperatives }\end{array}$ & 6 & 27.3 & Optional \\
\hline $\begin{array}{l}\text { TSB: Designing the suitable test types of the } \\
\text { lesson }\end{array}$ & 6 & 27.3 & Optional \\
\hline TSC: Referring back to the activities in Move 3 & 16 & 72.7 & Conventional \\
\hline M5: Presenting Assignment & 22 & 100 & Obligatory \\
\hline $\begin{array}{l}\text { TSA: Providing the instruction using } \\
\text { imperatives }\end{array}$ & 22 & 100 & Obligatory \\
\hline $\begin{array}{l}\text { TSB: Offering the task/homework about the } \\
\text { topic or the next lesson }\end{array}$ & 22 & 100 & Obligatory \\
\hline $\begin{array}{l}\text { TSC: Indicating the sources/references for the } \\
\text { next lesson }\end{array}$ & 7 & 31.8 & Optional \\
\hline
\end{tabular}

From the short review of Table 2, the key findings emerged that based on Kanoksilapatham's (2005) criteria on move frequency classification, all the five moves occurred at a frequency of $100 \%$, thus regarded as 'Obligatory' in all the lesson plans. The communicative functions of the five moves are presented next.

\section{Setting Objectives}

This move is used to design precise aims in the lesson. It is a set of detailed descriptions of exactly what the learners are expected to be able to do at the end of the instruction. 


\section{Introducing Subject Matter}

The function of this move is to present the learning contents, resource information, and audio-visual aids to be used in delivering the lesson. Specifically, according to the results, this move includes the topic and subtopic of the lesson to be discussed, the references or sources, and the list of instructional materials to be used.

\section{Describing Procedure}

The objective of this move is to organize lesson activities and teaching strategies to run the classroom smoothly. This move dictates how both the writer/studentteacher and learners will work together. It explains how the writer/studentteacher effectively functions in the classroom and reduces classroom interruptions and discipline problems because it tells students how things will work. Therefore, it is the most detailed and longest move.

\section{Detailing Evaluation}

The purpose of this move is to offer evaluative methods about the lesson, which are normally in the form of a test. The test is a teacher-constructed type that is based on the objectives of the lesson. It may be both formal and informal.

\section{Presenting Assignment}

The main function of this final move is to plan an activity that will be done by the students after the lesson. This move reinforces and helps learners to retain information taught by the student-teacher in the classroom as well as to increase their general understanding of the topic.

It is worth noting that the finding of the move confirmation followed the mandate of the Commission on Higher Education (CHED) through its Memorandum that novice teachers must adhere to the structure of producing DLPs that have five main parts: Objectives, Subject Matter, Procedure, Evaluation, and Assignment (CHED, 2004; CHED, 2017). This could mean that the writers were aware of the five main parts of the lesson plans for the novice teachers that are mandated by CHED. Concurrently, the cooperating teachers, headteachers, and school principals assured that the writers conformed with the policy set by CHED by checking and verifying the lesson plans. In all the 22 lesson plans, it was found that the names and signatures of the student-teachers as the ones who produced the lesson plans were identified first, then the names and signatures of the in-service teachers (e.g., cooperating teachers, headteachers, and school principals) were identified as signatories or those who check the lesson plans. This finding is consistent with what was stated by Student-Teacher 2 during a focus group interview, "My lesson plans were strictly checked by my cooperating teacher, and she made sure that I followed the correct format." A similar pattern of results is confirmed by one of the investigators of the current study, who happened to be a member of the supervising committee for seven years, and could also attest to the truthfulness of this finding. The writers, from the first writing courses to the orientation programs before their Teaching Internship course, were ordered by their 
professors that they should follow the 5-part structure of the lesson plans as prescribed by CHED.

\subsection{Findings on the rhetorical pattern of moves}

The rhetorical pattern of the moves was Move $1 \rightarrow$ Move $2 \rightarrow$ Move $3 \rightarrow$ Move $4 \rightarrow$ Move 5 , which is similar to the five-structure outline set by DepEd and $\mathrm{CHED}$ for novice lesson planners. Figure 1 shows the succession of moves.

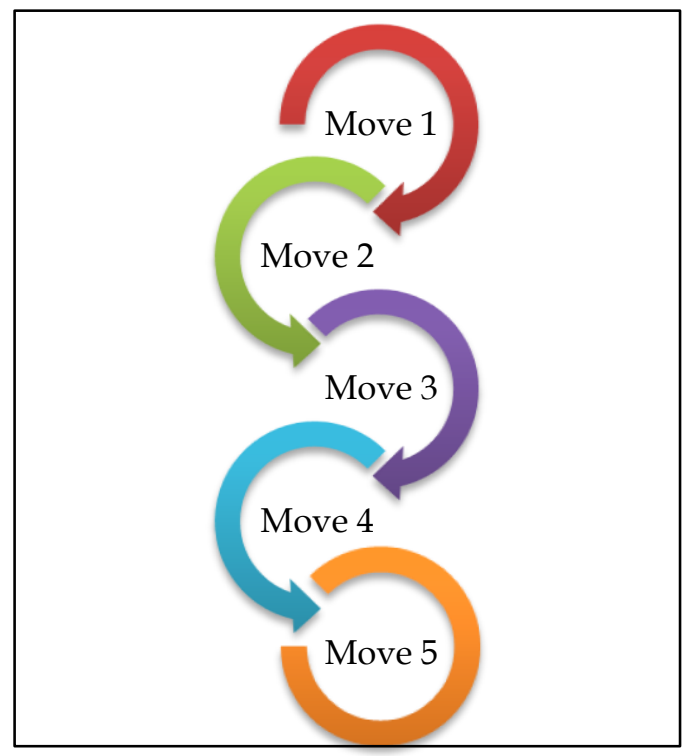

Figure 1. A rhetorical pattern of moves

Figure 1 displays that there was only one move pattern identified in each of the 22 Detailed Lesson Plans (DLPs). It means that the student-teachers and the other concerned signatories of the lesson plans strictly followed the prescribed format set by CHED for the student-teachers.

\subsection{Findings on the teaching strategies of Move 1}

Move 1 had two identified teaching strategies. Excerpts from the data, communicative goals, linguistic and mechanical clues or signals, and rhetorical patterns are presented.

Teaching Strategy A: Providing the starting signals or lead-in statements 1) At the end of the 50-minute class, the students should be able to:" (ST 5)

All of the 22 lesson plans had Teaching Strategy A, which was categorized as 'Obligatory' move. Its communicative function is to offer an introductory statement to open up the specific lesson goals. All of the student-teachers consistently made use of identical linguistic signals or expressions: At the end of to open the statement, and the infinitive to with a mechanical clue: colon (:) to close.

Teaching Strategy B: Listing the lesson goals as items

2) a. identify the different literary devices,

b. participate actively in the given tasks,

c. cite the importance of using literary devices in our everyday life. (ST 4) 
3) 1. determine the difference between rhyme and rhythm of poetry.

2. identify the rhyme and rhythm of a poem.

3. compose a poem that has a regular rhyme and rhythm.

4. interpret their poems through hand painting." (ST 13)

All of the 22 lesson plans had Teaching Strategy B, which was considered as 'Obligatory' move. Its communicative goal is to enumerate the specific objectives of the lesson. Noticeably, the linguistic clues that the writers used were the present forms of a verb to begin the lesson goals. In itemizing the lesson goals, 12 or $54 \%$ utilized letters while 10 or $45 \%$ used numbers. It implies that either letter or number is allowed to itemize the lesson goals. Notably, the action verbs used were based on Bloom's (1956) Three Domains of Learning, which are (1) Cognitive Domain or commonly known as the mental skills, (2) Affective Domain that pertains on feelings or emotional areas, and (3) Psychomotor Domain that is known as manual or physical skills. Bloom (1956) provides a list of action verbs in each domain that can be used in writing the lesson objectives, and these verbs are all measurable and can be utilized in writing the learning objectives of a lesson planner depending on the nature of the lesson and level of the learners. Correspondingly, when the participants of a focus group interview were asked on how they produced the parts of the lesson plan, Student-Teacher 4 responded that in writing the objectives, they followed the K-12 Basic Education Curriculum (BEC) Guide wherein a verb list is attached. As for the rhetorical pattern of the two teaching strategies, it is found that they followed a linear pattern. This finding could represent that the student-teachers set the objectives by providing the starting signals and by listing the lesson goals as items.

\subsection{Findings on the teaching strategies identified in Move 2}

Move 2 had three identified teaching strategies. Excerpts from the data, communicative goals, linguistic and mechanical clues or signals, and rhetorical patterns are presented below.

Teaching Strategy A: Specifying the topic to be discussed

4) Topic: Introduction to Literature

Subtopic: Prose and Poetry (ST 19)

All of the 22 lesson plans had 'Obligatory' Teaching Strategy A. Its communicative purpose is to present the topic and subtopic to be discussed. The findings reveal that all of the lesson plans had the main topic that was presented first, and the subtopic came next. The subtopic was the specific area, and the topic was the general area to be discussed. For instance, in the excerpt from the lesson plan of Student-Teacher 19, the main topic was Introduction to Literature, and the subtopic was Prose and Poetry. Teaching Strategy A can be signaled by words such as Topic, Subtopic and, by a colon (:).

Teaching Strategy B: Indicating the references of the textbooks or other sources of information to be used

5) Reference: Celebrating Diversity through World Literature: Grade 10 Module Author: Department of Education

Pages: 423-431 (ST 4) 
6) References: 1. Grade 10 English Learner's Material Diversity: Celebrating Multiculturalism through World Literature

2. An Adaptation of EA Poe's The Cask of Amontillado (online)

Authors: $\quad$ 1. Department of Education (DepEd)

2. The University of Utah, a YouTube video clip

Pages: $\quad$ 1. $116-125$

2. https://www.youtube.com/watch?v=VRUnc2sAKNU (ST 9)

This 'Obligatory' Teaching Strategy B is aimed to give details on the sources of information used in teaching the topic. The linguistic clue was the use of Reference, Author and Pages, and the mechanical clue was a colon (:). An interesting point in this teaching strategy is that if there were two or more references, numbers would be used to list them sequentially. For instance, in the excerpt from the lesson plan of Student-Teacher 9, she utilized two references: a textbook and an online source. The textbook was listed as 1 , and the online source was 2 .

Teaching Strategy C: Listing the instructional materials to be utilized

7) Instructional materials: paper strips, LCD projector, LED TV (ST 4)

8) Audio-visual aids: fact wrap, electro-board, balloons, boxes (ST 21)

Teaching Strategy $\mathrm{C}$ was categorized as 'Obligatory'. Its communicative function is to enumerate the learning tools to be utilized in teaching the topic. Based on the findings, various instructional materials were enumerated in this teaching strategy. Fifteen (68\%) out of the 22 lesson plans used 'instructional materials' while seven $(31.8 \%)$ utilized 'audio-visual aids'. This could imply that both of them are accepted in writing this teaching strategy. For a more detailed linguistic feature, Figure 2 displays a list of the instructional materials used by the student-teachers.

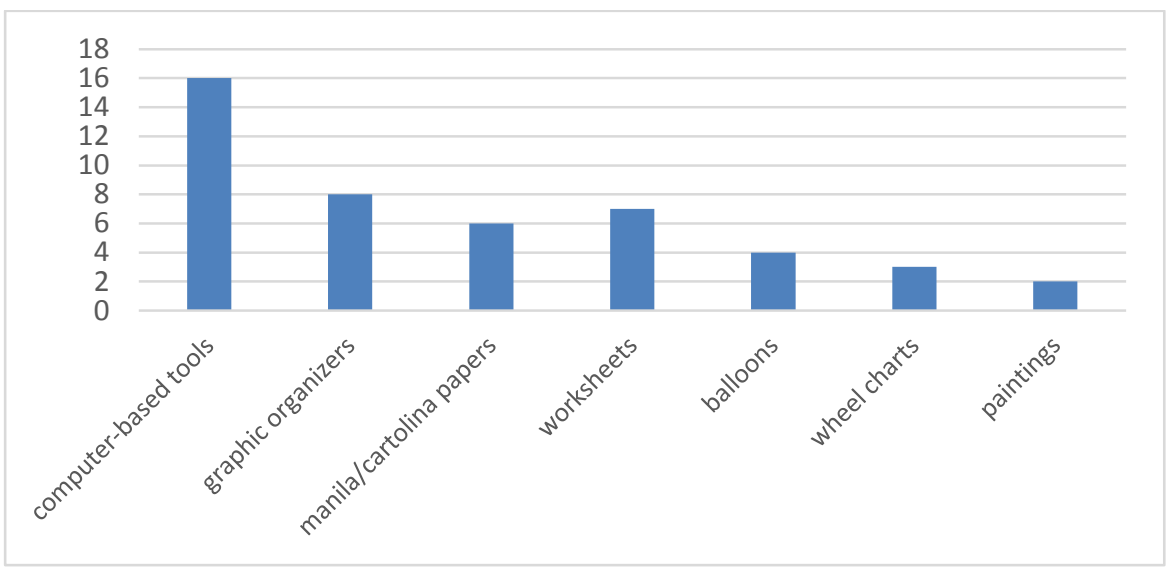

Figure 2. Common instructional materials

From Figure 2, it could be gleaned that there was a big gap between the computer-based tools (16 or $72.7 \%)$ and the traditional tools wherein the highest was graphic organizers, 8 or $36.4 \%$. This result demonstrates the importance of Information and Communication Technology (ICT) in teaching English topics,

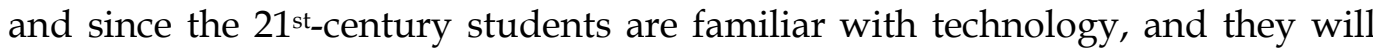
learn better within a technology-based environment, the ICT integration in schools, specifically in the teaching-learning process is vital. This result is 
broadly in line with the studies of Chaaban, Du and Ellili-Cherif (2019), Jamieson-Proctor et al. (2013) and Yeung, Tay, Hui, Lin and Low (2014) which highlight that the use of technology in teaching contributes a lot in the pedagogical aspects in which the application of ICT will lead to effective learning with the help and support from ICT elements and components. During the interview, Student-Teacher 5 stated that the students are motivated to study and participate in the class activities if ICT is integrated into teaching, that is why she made sure that ICT is always part of her plans. In the field note of the investigator, it was indicated that when Student-teacher 5 was sharing about ICT, all of the participants looked at her and nodded their heads that could indicate agreement or acceptance. This head gesture made the investigators realize that all of the six participants have similar experiences concerning integrating ICT in planning and teaching, respectively.

Furthermore, as for the rhetorical pattern of the three teaching strategies, it is found that they followed a linear pattern. It means that in introducing the subject matter, the student-teachers specified first the topic, then indicated the references of the textbooks or other sources, and finally listed the materials to be used.

\subsection{Findings on the teaching strategies identified in Move 3}

Move 3 had 19 identified teaching strategies. Out of the 19 identified teaching strategies, nine were 'Obligatory', seven were 'Conventional', and three were 'Optional'.

Teaching Strategy A: Listing the activities

9) A. Preliminary
a. Prayer
b. Greetings
c. Checking of Attendance
d. Checking of Assignment (ST 4)

10) 2. Discussion

3. Group Activity

4. Generalization (ST 16)

This 'Obligatory' Teaching Strategy A was employed in all the 22 lesson plans. Its communicative goal is to detail the tasks to be performed in the class. There were two ways of listing the activities, which were through letters and numbers. Of all the teaching strategies identified in Move 3, the investigators consider that Teaching Strategy A is the most important teaching strategy because it serves as the guide of the following teaching strategies. Teaching Strategy A always comes first before the other teaching strategies.

Teaching Strategy B: Offering the guiding scripts

11) c. Checking of Attendance

Tap the shoulder of the one on your right. Now, tap the one on your left. Check if your seatmate is present. (ST 5)

Teaching Strategy B was 'Obligatory', and its communicative purpose is to provide a set of instructions for the lesson planner. It serves as a guiding script of the student-teacher in realizing all the activities of the lesson. Based on 
Excerpt 11, underneath each activity was a set of instructions to achieve its communicative function. The linguistic clue of this teaching strategy was the consistent use of imperatives.

Teaching Strategy C: Providing the activities' instructions using imperatives

12) Based on the essay that you've read, make a word cloud...place it in a white paper...write a simple explanation...report your work." (ST 6)

Instructions underneath each activity were found in the 22 lesson plans, which was regarded as 'Obligatory'. Its communicative role is to give instructions about the activities. Based on Excerpt 12, the linguistic clue was that imperatives, which are highlighted in the excerpts, were used as starting signals of the instructions.

Teaching Strategy D: Predicting the students' responses

$$
\text { Teacher's Activity Students' Activity }
$$

$\begin{aligned} & \text { What did we discuss in the last } \\ & \text { meeting? }\end{aligned}$
$\begin{aligned} & \text { Sonnet } 41 \text {, Those pretty wrongs } \\ & \text { that liberty commits by William } \\ & \text { Shakespeare, Ma'am. }\end{aligned}$
What did we do to that sonnet?
$\begin{aligned} & \text { We identified the rhyme and the } \\ & \text { meter of Sonnet } 41, M a^{\prime} \text { am. }\end{aligned}$

The function of this 'Obligatory' teaching strategy is to anticipate the possible reply in every statement raised by the lesson planner. As shown in the excerpts, every action or statement that was identified beneath the Teacher's Activity column needed possible responses from the students. The linguistic clue in this teaching strategy was the statements under Teacher's Activity were in the question form starting with What, When, Who, Where, Which, Why, and How. In the Students' Activity, on the other hand, the statements were written in sentence responses to the questions that were asked.

Teaching Strategy E: Preparing the classroom/students

14) I think you are now ready for a group activity, but before that, I want you to Get along; Respect others; On task; Use quiet voices; Participate; Stay in your group. (ST 3)

Teaching Strategy E occurred in 19 out of the 22 lesson plans (89.4\%), which was 'Conventional', and its communicative goal is to arrange and/or set up the students as well as the appearance of the classroom. Out of these 19 lesson plans, 16 or $84.21 \%$ made use of linguistic signals, before we start and before that to prepare the students or classroom. This teaching strategy provides the rules and regulations that must be followed by the students. The possible physical appearance of the classroom (e.g., seating arrangement, instructional materials arrangement, among others) was also identified in this teaching strategy.

Teaching Strategy F: Activating the students' prior knowledge

15) Ok, what did we do at the last meeting? I forgot the theme of that story. Kindly tell me something about that.

(ST 3) 
The purpose of this 'Conventional' teaching strategy (20/22 or 90.9\%) is to review the students' knowledge of the previous topic. All of the 20 DLPs recurrently used identical linguistic signals which were last and previous to express that a certain activity or lesson was done in the previous lesson.

Teaching Strategy G: Drawing the students' attention to the new lesson

16) Let's have a game called charade. I will be acting out two keywords (happy, a prince) for you to guess to form a title of a classic short story written by Oscar Wilde. The first one who can guess the right title will be given a prize. (ST 15)

Teaching Strategy G was 'Conventional' (17/22 or $77.3 \%$ ), and its role is to encourage the students' involvement in the new topic. Future tense, as a linguistic clue, was used extensively.

Teaching Strategy H: Presenting the new topic

17) Very good. That is the lesson that we are going to discuss today. (ST 4)

The communicative function of this 'Obligatory' teaching strategy is to introduce the topic to be discussed. In the 22 lesson plans, this teaching strategy was identified right after Teaching Strategy J. In Excerpt 17, Teaching Strategy J, Very good, was shown first. Then, Teaching Strategy $\mathrm{H}$, That is the lesson that we are going to discuss today., was identified next. It is made possible because Teaching Strategy $G$ required a student's response that was identified as Teaching Strategy D, which was automatically followed by Teaching Strategy J. This teaching strategy pattern is thoroughly discussed in Figure 3. Adverbs of time (e.g., today, now, at present) were used as linguistic signals.

Teaching Strategy I: Discussing the topic

18) There are different types of literary devices. These are...

Teaching Strategy I was categorized as 'Obligatory'. The communicative goal of this teaching strategy is to talk about the topic. All of the statements were written in the present tense.

Teaching Strategy J: Praising the students' answers/performance

19) Exactly..., Good job..., Precisely..., Very good..." (ST 4)

The purpose of 'Obligatory' Teaching Strategy J is to reward the students by giving encouraging words for every response that they make. Its category suggests that teacher's praise is an efficient tool to motivate students, and it must always be a part not only in the lesson plan but also in the teaching-learning process. This teaching strategy is the most frequently identified teaching strategy. This frequent occurrence is not surprising at all because in every predicted response as identified in Teaching Strategy C, there was a corresponding reaction or response from the student-teacher and that was a praise as described in Teaching Strategy J. Adjectives of quality (e.g., perfect, excellent, great, and good); and adverbs of affirmation (e.g., precisely and exactly) signaled this teaching strategy. 
Teaching Strategy K: Foreseeing the possible classroom scenes using parentheses 20)

\section{Teacher's Activity}

I have here balloons and inside each balloon is a set of questions. Go to your group stations and pop out the balloons.
Students' Activity

(The students pop up the balloons in the four corners of the room.) (ST 19)

The role of this 'Conventional' teaching strategy (18/22 or $81.8 \%)$ is to predict what will happen in the classroom. The noticeable mechanical signal in this teaching strategy was the use of parentheses [()]. The present tense was frequently used in this teaching strategy.

Teaching Strategy L: Assigning the students' roles

21) Joyce, kindly lead us a Prayer. Class monitor, please check the attendance. (ST 3)

Teaching Strategy L, which was categorized as 'Obligatory', has a function to delegate tasks to the students. There were three identified linguistic clues in this teaching strategy: (1) common nouns (e.g., class monitor, secretary, leader, etc.) or proper nouns (e.g., Susan, Joyce, Carlo, etc.); (2) imperatives to assign the roles and the imperatives written right after the words used in making requests (e.g., kindly and please); and (3) future tense.

Teaching Strategy M: Addressing the students

22) Okay, my dear students, kindly bring out a sheet of paper. (ST 11)

The communicative goal of 'Obligatory' Teaching Strategy M is to offer a group name for the whole class. Collective names for the whole class (e.g., class, dear students, friends) were used as linguistic clues.

Teaching Strategy N: Mentioning the scoring rubric/system

23) The scoring rubric for this activity is presented on the screen.

This teaching strategy was 'Optional' (14/22 or 59.1\%), and its purpose is to present a scoring system to be used in rating the group performance of the students. The frequently used linguistic clues in this teaching strategy were scoring rubric, scoring system, and criteria.

Teaching Strategy O: Indicating the figures/images related to the activities 24) Describe the photographs that are shown on the screen.

The role of Teaching Strategy O, categorized as 'Conventional' (18/22 or 81.8\%), is to present pictures or graphs needed in the activities. In this teaching strategy, photographs, graphs, and diagrams were identified in the lesson plans. The picture clues that were commonly identified were graphs and photographs.

Teaching Strategy P: Asking closing questions

25) Based on our discussion and activities, what have you learned?"

This teaching strategy was regarded as 'Optional' (9/22 or $40.1 \%)$, and its function is to raise concluding questions about the topic discussed. Interrogative 
sentences that determined whether the students understood the lesson or not were used to signal this teaching strategy.

Teaching Strategy Q: Assessing the students' knowledge about the lesson 26) I have here a set of paper strips, get one and write a word that could summarize our lesson. Let us see if you have understood our lesson. (ST 5)

Teaching Strategy Q was identified in 20 out of the 22 lesson plans (90.1\%), thus 'Conventional', and its communicative goal is to test the students' understanding of the topic. In this teaching strategy, an activity was designed by the student-teacher as a form of evaluation wherein a scoring rubric/system was utilized. The clue suggests that the student-teachers in this teaching strategy wanted to check if the learners understood the lesson.

Teaching Strategy R: Integrating the values of the lesson

27) Okay, class. Kindly share the morals of the poem. (ST 13)

'Obligatory' Teaching Strategy R's communicative purpose is to incorporate the moral standards that can be drawn from the topic. The moral values are not only drawn from the literature topics (e.g., poems, stories, novels, etc.) but also English skill topics (e.g., writing, speaking, listening, reading, and grammar). For instance, in Excerpt 27, the poem that the teacher discussed was "Mending Wall" by Robert Frost. The predicted student's response to the statement of the teacher, Okay, class. Kindly share the morals of the poem., was goodwill towards others. The clues were values, morals, and ethics.

Teaching Strategy S: Preparing the students for Move 4

28) All right, if you don't have any questions, let's see whether you understand our lesson through a test. The slide contains questions for you to answer. (ST 5)

Teaching Strategy S was considered as 'Optional' $(11 / 22$ or $50 \%)$, and its role is to set the students to move in the next section of the lesson plan, which is Move 4, Detailing Evaluation. Its linguistic clues were next is a quiz and have a test. These clues signal the students that the next section is a test or evaluation for them.

As for the rhetorical structure of the teaching strategies in Move 3, it is found that they followed a non-linear teaching strategy pattern. To explain this phenomenon, the teaching strategies in Move 3 recurred in different activities. For instance, Teaching Strategy $\mathrm{C}$ was identified in every listed activity in Move 3. Other examples are the Teaching Strategy J and Teaching Strategy K that occurred in all the activities described in Move 3. As a consequence, it is construed that the teaching strategies underneath Move 3 followed a non-linear rhetorical pattern, quite the reverse of the other moves' teaching strategies that followed a linear pattern. However, there were identified teaching strategies that recurred in Move 3. That is, they were characterized by the recurrence of one or more teaching strategies, and that they indicated a cyclical structure. This frequent occurrence of teaching strategies, which showed a cyclical pattern, is inspired by Peacock's (2002) move cycles in the Discussion section of research articles. To further illustrate this point, Figure 3 displays the recurrence of some of the identified teaching strategies of Move 3. 
TS A: Listing the activities

TS B: Offering the guiding scripts

TS C: Providing the activities' instructions using imperatives

TS D: Predicting the students' responses

TS J: Praising the students' answers/performance

TS B: Offering the guiding scripts

TS C: Providing the activities' instructions using imperatives

TS J: Praising the students' answers/performance

Figure 3. Teaching strategy cycle of teaching strategies in Move 3

Eight teaching strategies recurred in Move 3, which were described as the teaching strategy cycle. The teaching strategies involved in the cyclic structure were Teaching Strategy B, Teaching Strategy C, and Teaching Strategy J. These three teaching strategies were repeated in the sequence, TSA-TSB-TSC-TSD-TSJTSB-TSC-TSJ. The variety of patterns suggests that writers may organize Move 3 and its constituent teaching strategies with a certain amount of flexibility and freedom. Accordingly, there were other sequences identified underneath Move 3. Interestingly, the most noticeable feature in these sequences is that all of them required the same teaching strategy pattern, which was Teaching Strategy D and Teaching Strategy J. Figure 4 displays the identified teaching strategy sequences that require the same teaching strategy pattern, which is Teaching Strategy D and Teaching Strategy J.

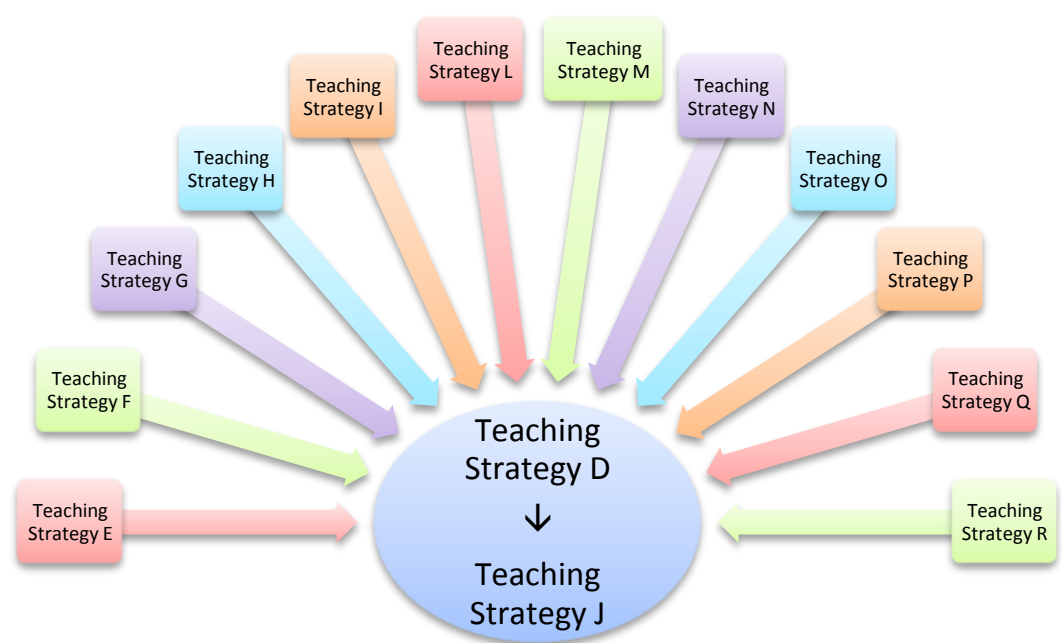

Figure 4. Teaching strategies followed by a common teaching strategy pattern 
There were 12 teaching strategies identified in Move 3 that always followed by a common pattern, which was Teaching Strategy D and Teaching Strategy J. This represents that most of the teaching strategies identified in Move 3 required Teaching Strategy D and Teaching Strategy J. For instance, once Teaching Strategy E is identified, expect that Teaching Strategy D and Teaching Strategy J are written next. This phenomenon also happened in other teaching strategies that are shown in Figure 3. However, two identified teaching strategies, Teaching Strategy K and Teaching Strategy S, did not require Teaching Strategy $\mathrm{D}$ and Teaching Strategy J. It is noteworthy to mention that this non-occurrence of Teaching Strategy D and Teaching Strategy J after Teaching Strategy K and Teaching Strategy $S$ indicates that they do not require possible responses from the students (Teaching Strategy D). The findings show that there were 18 out of the 22 lesson plans $(81.8 \%)$ that had Teaching Strategy K, but after the exploration of these 18 lesson plans, it was found that all of them did not require Teaching Strategy D.

\subsection{Findings on the teaching strategies identified in Move 4}

Move 4 had three identified teaching strategies. Excerpts, communicative goals, linguistic clues or signals, and rhetorical patterns are presented.

Teaching Strategy A: Providing the instructions using imperatives

29) ... arrange the following words according to their intensity. Present them in a cline. (ST 5)

Teaching Strategy A was 'Optional' (6/22 or 27.3\%), and its function is to offer a guideline of the test to be facilitated. As highlighted in the excerpts, imperatives as a linguistic clue were used to provide the instruction of the evaluation.

Teaching Strategy B: Designing the suitable test types of the lesson 30) ...complete the following sentences using the words from the clines. (ST 5)

31)...match the words in Column A to the statements in Column B. (ST 15)

This 'Optional' teaching strategy occurred in 6 out of the 22 lesson plans, and its goal is to provide an appropriate evaluation type of the lesson. The identification of the test type relied on two things: the first was imperatives, and the second was the keywords in the instruction. For instance, in Excerpt 30, the imperative used was complete and the remaining keywords were following sentences using the words. Therefore, the test type that was used by Student-teacher 5 in this lesson plan was sentence completion or cloze test. On the other hand, based on Excerpt 31, the imperative was match and the other keywords in the instruction were Column A to the statements in Column B., which could signify that the test was matching type. Linguistic clues used to identify this teaching strategy were statements that showed what type of test and imperatives.

Teaching Strategy C: Referring back to the activities in Move 3

32) The enrichment activity serves as the evaluation. (ST 3)

This 'Conventional' teaching strategy occurred in 16 out of the 22 lesson plans $(72.7 \%)$, and its purpose is to restate the activity in Move 3, Describing Procedure as the evaluation of the lesson. It was found that there was a 
consistent use of serves, group activity. The statements were all written in the present tense.

The results show that the first two teaching strategies were 'Optional' because 16 out of the 22 lesson plans $(72.7 \%)$ had Teaching Strategy C, which was categorized as 'Conventional'. It means that if the lesson plans have Teaching Strategy A and Teaching Strategy B, they do not have Teaching Strategy C. Conversely, if the lesson plans have Teaching Strategy C, they do not have Teaching Strategy A and Teaching Strategy B. This phenomenon happens because the typical class time for English is only one hour per session, so the lesson planners who are aware of this schedule decide that the activity which was previously done in the 'Procedure' section, Move 3, would serve as the evaluation that is detailed in Move 4. This result was also mentioned in the teaching journal of Student-teacher 6, "It was timely that the enrichment activity served as the evaluation because the time was not enough."

Based on the analysis of the teaching strategy pattern of the three teaching strategies of Move 4, it was interpreted that they followed a linear pattern. Teaching Strategy A and Teaching Strategy B followed a linear rhetorical pattern, which could suggest that Teaching Strategy A requires Teaching Strategy B. Teaching Strategy $\mathrm{C}$ did not belong to the rhetorical pattern of the first two teaching strategies because if a lesson plan had Teaching Strategy C, Teaching Strategies A and B would not be identified in Move 4. On the other hand, if the lesson plan had Teaching Strategy A and Teaching Strategy B, Teaching Strategy $\mathrm{C}$ would not be identified in Move 4 .

\subsection{Findings on the teaching strategies identified in Move 5}

Move 5 had three identified teaching strategies. Excerpts, linguistic features, and rhetorical patterns of these teaching strategies are provided in the next section. Teaching Strategy A: Providing the instruction using imperatives

33) Next meeting, proceed to your groups. In a Manila paper, write... (ST 4)

Teaching Strategy A is 'Obligatory', and its role is to offer a direction that describes the homework. The signals used were imperatives (e.g., proceed, write) and time elements (e.g., next meeting, tomorrow), which signify that the given task was done after the class or in the future.

Teaching Strategy B: Offering the task/homework about the topic or the next lesson

34) ...short script about the message of the story that we had discussed. (ST 4)

35) characters and characterizations in the short story... (ST 11)

This 'Obligatory' teaching strategy's role is to describe the specific activity to be done by the students. It informs the students on what particular assignment will be done. For instance, in Excerpt 34, the keywords script and message imply that the assignment was scriptwriting. Also, in Excerpt 35, the keywords characters, characterizations, and Footnote to Youth entail that the assignment was reading the story and identifying the characters and their characterizations. The linguistic cue was the keywords, which were highlighted in the excerpts, that indicated 
what type of homework was given to the students (e.g., script, characters, and characterizations).

There were two noticeable features of the teaching strategies identified in Move 5. First, if the reference or source of the topic to be discussed is the same as Teaching Strategy B of Move 2, there is no need to restate it in Teaching Strategy C of Move 5. One best example of this phenomenon is Excerpt 34, where Move 5 had only Teaching Strategy A and Teaching Strategy B because the reference or source of the homework was the same to the reference or source of the topic discussed as described in Teaching Strategy $\mathrm{C}$ of Move 2. This could imply that the given assignment, which was scriptwriting about the message of the story, was still connected to the topic described in the lesson plan of Student-Teacher 4. The second feature is if the assignment or homework is a new lesson or has no connection to the previous topic, then a new reference or source is introduced. The following excerpts show the lesson plan of Student-Teacher 18 that had all the teaching strategies.

Move 5, Teaching Strategy A: Providing the instruction using imperatives 36a) Read the speech of Severn Suzuki and find out...

Move 5, Teaching Strategy B: Offering the task/homework about the topic or next lesson

36b) ...how young members of society live out their role as global citizens.

Move 5, Teaching Strategy C: Indicating the sources/references for the next lesson

37c) Reference: Celebrating Diversity through

World Literature: Grade 10 Module

Author: Department of Education

Pages: 489-491

The DLP of Student-Teacher 18 had all the three teaching strategies. It was found that ST 18's reference reported in Teaching Strategy B, Indicating the references of the textbooks and other sources of information to be used underneath Move 2 was different from the reference described in Teaching Strategy C, Indicating the sources/references for the next lesson of Move 5. It means that the given assignment, the Speech of Severn Suzuki, was a new topic for the next class meeting. Thus, there was a need to include the reference or source of the topic. The three teaching strategies followed a linear pattern, which could mean that in presenting assignment, a lesson planner offers first the instruction, then provides the task/homework, and finally indicates the sources or references. However, as shown in Table 2, not all the lesson plans had Teaching Strategy C. The results show that there were 7 or $31.8 \%$ out of the 22 lesson plans that had three teaching strategies compared to 15 or $68.2 \%$ that had only two teaching strategies. This could imply that the assignments of the 7 lesson plans had different references or sources identified in Teaching Strategy B of Move 2, while the assignments of the other 22 lesson plans had identical references/sources described in Teaching Strategy B of Move 2. 


\section{Conclusion}

In this study, the 22 Detailed Lesson Plans (DLPs) were confirmed to have five main parts or moves, which conforms with the 5-part lesson planning policy prescribed by CHED for novice teachers. The teaching strategies underneath the four moves: 1) Setting Objectives; 2) Introducing Subject Matter; 4) Detailing Evaluation; and 5) Presenting Assignment followed the same linear order, while the teaching strategies of Move 3, Describing Procedure had no linear pattern. Nonetheless, there were identified teaching strategies in Move 3 that formed a cyclical structure (see Figure 3) and a common teaching strategy pattern (see Figure 4). The variety of patterns suggests that writers may organize Move 3's teaching strategies with a certain amount of flexibility and freedom. The investigators included linguistic features because these may elicit suggestions on how teaching strategies underneath the moves are produced. This idea is backed up by Nwogu (1997) and Yang and Allison's (2003) concept on move analysis, or move confirmation and teaching strategy identification in this study, that a text segment made up of a bundle of linguistic features which give the segment a uniform orientation and signal the content of discourse in it.

Based on this concept, the investigators firmly believe that the 5-part structure and linguistic features of a DLP could lead to the realization of moves and their corresponding teaching strategies, which could be a key to develop a text frame in planning a lesson. Thus, a DLP framework, which is obtained from the indepth exploration of the 22 DLPs, is developed as a guide to offer a frame for structuring the planning of lessons and a pool of words that can help teachers in lesson planning.

\begin{tabular}{|l|}
\hline \multicolumn{1}{|c|}{ Moves and Teaching Strategies of Detailed Lesson Plans } \\
\hline$\checkmark$ Move 1: Setting Objectives \\
\hline$\checkmark$ Teaching Strategy A: Providing the starting signals or lead-in statements \\
\hline$\checkmark$ Teaching Strategy B: Listing the lesson goals as items \\
\hline$\checkmark$ Move 2: Introducing Subject Matter \\
\hline$\checkmark$ Teaching Strategy A: Specifying the topic to be discussed \\
\hline$\checkmark$ Teaching Strategy B: Indicating the references of the textbooks to be used \\
\hline$\checkmark$ Teaching Strategy C: Listing the instructional materials to be utilized \\
\hline$\checkmark$ Move 3: Describing Procedure \\
\hline$\checkmark$ Teaching Strategy A: Listing the activities \\
\hline$\checkmark$ Teaching Strategy B: Offering the guiding scripts \\
\hline$\checkmark$ Teaching Strategy C: Predicting the students' responses \\
\hline$\checkmark$ Teaching Strategy D: Providing the activities' instructions using imperatives \\
\hline @Teaching Strategy E: Preparing the classroom/students \\
\hline @Teaching Strategy F: Activating the students' prior knowledge \\
\hline @Teaching Strategy G: Drawing the students' attention to the new lesson \\
\hline$\checkmark$ Teaching Strategy H: Presenting the new topic \\
\hline$\checkmark$ Teaching Strategy I: Discussing the topic \\
\hline$\checkmark$ Teaching Strategy J: Praising the students' answers/performance \\
\hline @Teaching Strategy K: Foreseeing the possible classroom scenes using parentheses \\
\hline$\checkmark$ Teaching Strategy L: Assigning the students' roles \\
\hline$\checkmark$ Teaching Strategy M: Addressing the students \\
\hline +Teaching Strategy N: Mentioning the scoring rubric/system \\
\hline
\end{tabular}




\begin{tabular}{|l|}
\hline OTeaching Strategy O: Indicating the figures/images related to the activities \\
\hline +Teaching Strategy P: Asking closing questions \\
\hline OTeaching Strategy Q: Assessing the students' knowledge about the lesson \\
\hline OTeaching Strategy R: Integrating the values of the lesson \\
\hline +Teaching Strategy S: Preparing the students for Move 4 \\
\hline$\checkmark$ Move 4: Detailing Evaluation \\
\hline +Teaching Strategy A: Providing the instructions using imperatives \\
\hline +Teaching Strategy B: Designing the suitable test types of the lesson \\
\hline OTeaching Strategy C: Referring back to the activities in Move 3 \\
\hline$\checkmark$ Move 5: Presenting Assignment \\
\hline$\checkmark$ Teaching Strategy A: Providing the instruction using imperatives \\
\hline$\checkmark$ Teaching Strategy B: Offering the task/homework about the topic or the next lesson \\
\hline +Teaching Strategy C: Indicating the sources/references for the next lesson \\
\hline Note: $\checkmark$-Obligatory; C-Conventional; +-Optional
\end{tabular}

Figure 5. A Detailed Lesson Plan Framework

\section{Pedagogical implication}

The key purpose for any genre analysis is the central role it plays in the English Language Teaching (ELT) and English for Specific Purposes (ESP) courses, and that is to help learners acquire what Bhatia (2004) called "generic competence," which focuses on "the ability to identify, construct, interpret, and successfully exploit a specific repertoire of professional disciplinary or workplace genres" (p.145). Thus, the pedagogical implications of this study are aligned with the potential significance of the results, informing Teacher Education curriculum design in the Philippines specifically the Secondary Education Program (SEP) in English, which are focused on helping ESL teacher education students or preservice teachers to produce well-written Detailed Lesson Plans (DLPs) using the framework proposed by the investigators. Integrating the lesson plan genre in the Secondary Education (SEd) curriculum would be a practical option for the TEI professors, or holding specialized seminars or workshops for all the members of the identified discourse community may provide information for developing lesson plans. In due course, when the English student-teachers would be hired as in-service teachers, they could produce DLPs without much difficulty because they have a rhetorical framework as their reference in planning their lessons. This could also help them to get a higher rank or position because lesson plans serve as evidence of a teacher's professional performance for promotion purposes in the Philippines. They are asked to include lesson plans, along with other materials, as part of their Results-based Performance Management System (RPMS) Portfolios to support their annual performance because a collection of DLPs is considered an imperative component of the Individual Performance Commitment and Review (IPCR) of the teachers (DepEd, 2016.). Finally, teachers applying for new jobs might be asked to submit lesson plans as part of their job application so that employers can get a sense of their organizational skills, teaching style, and competence.

Therefore, understanding and applying the proposed framework, the rhetorical patterns, and the linguistic features in lesson planning will enable novice lesson planners to organize their work effectively, which leads to increased chances of producing well-planned lessons. 


\section{References}

Basturkmen, H. (2012). A genre-based investigation of discussion sections of research articles in dentistry and disciplinary variation. Journal of English for Academic Purposes, 11, 134-144. http://dx.doi.org/10.1016/j.jeap.2011.10.004

Biber, D., Conner, U., \& Upton, T. A. (2007). Discourse on the move: Using corpus analysis to describe discourse structure. Netherlands: John Benjamins Publishing Company.

Bhatia, V. K. (2004). Worlds of written discourse: A genre-based view. New York: Continuum International Publishing Group.

Bloom, B. S. (1956). Taxonomy of educational objectives: The classification of educational goals. New York, NY: Longmans, Green.

Cavanagh, M., Barr, J., Moloney, R., Lane, R., Hay, I., \& Chu, H. (2019). Pre-service teachers' impact on student learning: planning, teaching, and assessing during professional practice. Australian Journal of Teacher Education, 44(2), 66-81. http://dx.doi.org/10.14221/ajte.2018v44n2.5

Chaaban, Y., Du, X., \& Ellili-Cherif, M. (2019). Influence of the practicum experience on student-teachers' beliefs about their role in EFL classrooms. International Journal of Learning, Teaching and Educational Research, 18(9), 78-95. http://dx.doi.org/10.26803/ijlter.18.9.4

Commission on Higher Education. (2004). CMO No. 30, s. 2004, Revised policies and standards for undergraduate teacher education curriculum. Retrieved from http://www.ched.gov.ph

Commission on Higher Education. (2017). CMO No. 75, s. 2017, Policies, standards and guidelines for bachelor of secondary education. Retrieved from http://www.ched.gov.ph

Crookes, G. (1986). Towards a validated analysis of scientific text structure. Applied Linguistics, 7(1), 57-70. http://dx.doi.org/10.1093/applin/7.1.57

Department of Education (2007). DepED Order No. 3, s. 2007, Guidelines in the deployment of pre-service teachers in experiential learning: field study and practice teaching, Philippines: DepED.

Department of Education (2016). DepED Order No. 42, s. 2016, Policy guidelines on daily lesson preparation for the K to 12 basic education program. Philippines: DepED.

Department of Education (2017). DepED Order No. 42, s. 2017, National adoption and implementation of the Philippine professional standards for teachers. Philippines: DepED.

Huang, P., \& He, L. (2011). Comparative genre analysis of research methods in English and Chinese experimental research articles. Chinese Journal of ESP, 2(1), 22-27.

Hyland, K. (2000). Disciplinary discourse. Social interactions in academic writing. Harlow: Pearson Education.

Jamieson-Proctor, R., Albion, P., Finger, G., Cavanagh, R., Fitzgerald, R., Bond, T., \& Grimbeek, P. (2013). Development of the TTF TPACK survey instrument. Australian Educational Computing, 27(3), 26-35.

Jaroongkhongdach, W., Todd, R. W., Keyuravong, S., \& Hall, D. (2012). Differences in quality between Thai and international research articles in ELT. Journal of English for Academic Purposes, 11(3), 194-209. http://dx.doi.org/10.1016/j.jeap.2012.04.006

John, P. (2006). Lesson planning and the student-teacher: re-thinking the dominant model. Journal of Curriculum Studies, 38(4), 483-498. http:/ /dx.doi.org/10.1080/00220270500363620

Kanoksilapatham, B. (2005). Rhetorical structure of biochemistry research articles. $\begin{array}{llll}\text { English for Specific 269-292. } & \text { Purposes, }\end{array}$ 
http://dx.doi.org/10.1016/j.esp.2004.08.003

Li, L. J., \& Ge, G. C. (2009). Genre analysis: Structural and linguistic evolution of the English-medium medical research article (1985-2004). English for Specific Purposes, 28(2), 93-104. http://dx.doi.org/10.1016/j.esp.2008.12.004

Lim, J. M. H. (2006). Method sections of the management research article: A pedagogically motivated qualitative study. English for Specific Purposes, 25, 282309. http://dx.doi.org/10.1016/j.esp.2005.07.001

Lores, R. (2004). On RA abstracts: From rhetorical structure to the thematic organization. English for Specific Purposes, 23(3), 280-302. http://dx.doi.org/10.1016/j.esp.2003.06.001

Moradana, A., \&, Pourasadollahb, R. (2014). Teachers' thinking about their teaching: A critical study on Iranian TEFL teachers. Journal of Social and Behavioral Sciences, 98, 1194-1203. http://dx.doi.org/10.1016/j.sbspro.2014.03.534

Neuendorf, K. A. (2002). The content analysis guidebook. Thousand Oaks, CA: Sage.

Nguyen, T. T. L., \& Pramoolsook, I. (2014). Rhetorical structure of introduction chapters written by novice Vietnamese TESOL postgraduates. $3 \mathrm{~L}$ : Language, Linguistics and Literature, The Southeast Asian Journal of English Language Studies, 20(1), 61-74. http://dx.doi.org/10.17576/31-2014-2001-05

Nguyen, T. T. L., \& Pramoolsook, I. (2015). Citation in Vietnamese TESOL: Analysis of master's thesis introduction chapters. Asian ESP Journal, 11(1), 95-120.

Nwogu, K. N. (1997). The medical research paper: Structure and functions. English for Specific Purposes, 16(2), 119-138. http://dx.doi.org/10.1016/s0889-4906(97)853884

Ozturk, I. (2007). The textual organization of research article introductions in applied linguistics: variability within a single discipline. English for Specific Purposes, 26, 25-38. http://dx.doi.org/10.1016/j.esp.2005.12.003

Peacock, M. (2002). Communicative moves in the discussion section of research articles. System, 30, 479-497. http://dx.doi.org/10.1016/S0346-251X(02)00050-7

Peacock, M. (2011). The structure of the Methods section in research articles across eight disciplines. Asian ESP Journal, 7(2), 97-124.

Rozelle, J. J., \& Wilson, S. M. (2012). Opening the black box of field experiences: How cooperating teachers' beliefs and practices shape student-teachers' beliefs and practices. Teaching and Teacher Education, 28(8), 1196-1205. http://dx.doi.org/10.1016/j.tate.2012.07.008

Rusznyak, L., \& Walton, E. (2011) Lesson planning guidelines for student-teachers: A scaffold for the development of pedagogical content knowledge. Education as Change, 15(2), 271-285. http:/ / dx.doi.org/10.1080/16823206.2011.619141

Ruys, I., Keer, H. V., \& Aelterman A. (2012). Examining pre-service teacher competence in lesson planning on collaborative learning. Journal of Curriculum Studies, 44(3), 349-379. http://dx.doi.org/10.1080/00220272.2012.675355

Samraj, B. (2002). Introductions in research articles: variations across disciplines. English for Specific Purposes, 21, 1-17. http://dx.doi.org/10.1016/S0889-4906(00)00023-5

Schulze, J. M. (2016). Understanding the developing persuasive writing practices of an adolescent emergent bilingual through systemic functional linguistics: A case study. International Journal of Learning, Teaching and Educational Research, 15(10), 163-179.

Stoller, F. L., \& Robinson, M. S. (2013). Chemistry journal articles: An interdisciplinary approach to move analysis with pedagogical aims. English for Specific Purposes, 32(1), 45-57. http://dx.doi.org/10.1016/j.esp.2012.09.001

Swales, J. M. (1981). Aspects of article introductions. Birmingham, UK: The University of 
Aston, Language Studies Unit.

Swales, J. M. (1990). Genre analysis: English in academic and research settings. Cambridge: Cambridge University Press.

Taghipour, M. (2013). English teachers' attitudes towards lesson planning. The Iranian EFL Journal, 9(6), 354-363.

Thephavongsa, S. (2019). Enhancing the teaching skills of the multi-grade teachers through lesson study. International Journal of Learning, Teaching and Educational Research, 18(4), 71-87. http://dx.doi.org/10.26803/ijlter.17.4.5

Williams, J. (2009). Beyond the practicum experience. ELT Journal, 63(1), 68-77. http://dx.doi.org/10.1093/elt/ccn012

Wyatt, M. (2011). Teachers researching their own practice. ELT Journal. 65(4), 417-425. http://dx.doi.org/10.1093/elt/ccq074

Yang, R., \& Allison, D. (2003). Research articles in applied linguistics: Moving from results to conclusions. English for Specific Purposes, 22, 365-385. http://dx.doi.org/10.1016/S0889-4906(02)00026-1

Yeung, A. S., Tay, E., Hui, C., Lin, J. H., \& Low, E. (2014). Pre-service teachers' motivation in using digital technology. Australian Journal of Teacher Education, 39(3), 135-153. http://dx.doi.org/10.14221/ajte.2014v39n3.1

Yildirim, A. (2003). Instructional planning in a centralized school system: Lessons of a study among primary school teachers in Turkey. International Review of Education, 49(5), 523-543.

Zhang, B., Thuc, Q. B. T., \& Pramoolsook, I. (2012). Moves and linguistic realizations: English RA abstracts by Vietnamese agricultural researchers. Asian ESP Journal, 8(3), 126-149. 